\title{
Improving basin scale shallow landslide modelling using reliable soil thickness maps
}

\author{
Samuele Segoni • Guglielmo Rossi • Filippo Catani
}

Received: 28 January 2010/Accepted: 3 March 2011/Published online: 18 March 2011

(C) The Author(s) 2011. This article is published with open access at Springerlink.com

\begin{abstract}
Soil thickness is a well-known factor controlling shallow landsliding. Notwithstanding, its spatial organisation over large areas is poorly understood, and in basin scale slope analyses it is often established using simple methods. In this paper, we apply five different soil thickness models in two test sites, and we use the obtained soil thickness maps to feed a slope stability model. Validation quantifies how errors in soil thickness influence the resulting factor of safety and points out which method grants the best results. In particular, in our cases, slope-derived soil thickness patterns produced the worst slope stability assessment, while the use of reliable soil thickness maps obtained by means of a more complex geomorphologically indexed model improved shallow landslides modelling.
\end{abstract}

Keywords Soil thickness · Soil depth $\cdot$ Shallow landslides $\cdot$ Sensitivity $\cdot$ Factor of safety Infinite slope

\section{Introduction}

Shallow landslides and debris flows are dangerous phenomena responsible for a large number of casualties and economic losses (Schuster and Fleming 1986; Crosta 1998; Catani et al. 2005; Montrasio et al. 2009). Many efforts have been made to develop process-based models in order to assess slope stability at basin scale (Guzzetti et al. 1999, 2008). However, when trying to predict or model shallow landslides in a distributed way over large areas, one of the main problems is not the stability model itself, but the uncertainty in the spatial variability of the input parameters (Khazai and Sitar 2000; Savage et al. 2004; Guzzetti et al. 2007). There is large agreement on considering soil thickness as one of the most important factors controlling shallow landsliding (Johnson and Sitar 1990; Wu and Sidle 1995; Van Asch et al. 1999; Dietrich et al. 2008). Therefore, attention should be paid in choosing the right criterion to enter this parameter in basin scale slope stability models. To enter soil thickness in basin scale models, many authors rely on straightforward

S. Segoni $(\bowtie) \cdot$ G. Rossi · F. Catani

Earth Science Department, University of Firenze, Via la Pira 4, 50121 Florence, Italy

e-mail: samuele.segoni@unifi.it 
and simplistic solutions such as considering a spatially constant value in the whole studied area (Khazai and Sitar 2000; Savage et al. 2004), using soil thickness classes (Revellino et al. 2008), assigning a constant value for each geological formation encountered in the analysed site (Savage et al. 2004) or deriving a distributed soil thickness map from a single known topographic attribute such as the elevation (Saulnier et al. 1997) or the slope gradient (De Rose 1996; Salciarini et al. 2006). More complex methods that make use of multivariate statistical analyses (Gessler et al. 2000; Tesfa et al. 2009) or that employ process-based models (Casadei et al. 2003; Pelletier and Rasmussen 2009) are less frequently used as input data in large scale slope stability analyses because they are very sitespecific and require some effort to be correctly applied and calibrated over large areas.

The objective of this paper is to compare five methods of producing spatially variable soil thickness maps in order to: (1) understand the sensitivity of slope stability analysis to soil thickness; (2) discuss how error estimation in soil thickness models influences slope stability assessment; (3) evaluate which soil thickness model is more effective when used in conjunction with basin scale slope stability models. To fulfil these objectives, a slope stability model will be applied on a pixel-by-pixel basis using a variety of soil thickness maps each obtained using a distinct method. This experiment will be repeated in two test sites characterised by very different geological and geomorphological settings.

\section{Methodologies}

\subsection{Slope stability model}

The model used in our analysis takes inspiration from Iverson's model for landslides triggered by rain infiltration and couples a hydrological model based on a reduced form of Richards' equation with an infinite slope stability analysis (Iverson 2000). Due to the assumption needed to find the simplified solution for the Richards' equation, Iverson's model neglects the effect of soil suction on the overall effective cohesion. In this modified version, the additional cohesion due to suction in unsaturated soils has been included within the slope stability model. Moreover, the slope stability simulator used during this study allows us to find a solution not only for a single rainfall event but also for complex storms characterised by different and alternating intensities in both space and time. The stability model is implemented in a computer code designed to be applied in operational forecasting systems: The analyses are performed in near real time and the computations can be continued without restating the analysis from the beginning, whenever new rainfall data are available. In addition, the code can also be used for back analysis, simulating a historical rainfall event as in the present work. The computer code used is not yet available to the public, since still under final development status in a PhD thesis (Rossi in preparation). In this work a preliminary version was used (Leoni 2009). As every other model based on infinite slope theory, it is designed to be applied wherever soil coverage, compared to the underlying bedrock, exhibits a marked change in hydraulic properties.

The model can be divided in two independent parts: the hydrological tool that calculates the spatial pressure head distribution $\psi(Z, t)$ as a function of time $t$ and depth $Z$, and the stability analysis tool that supplies the distributed value of the factor of safety as outcome.

In the simplified solution of Richards' equations, pressure head $\psi(Z, t)$ is subdivided in two cases: during rainfall (Eq. 1) and after rainfall (Eq. 2) (Iverson 2000). 


$$
\begin{gathered}
\psi(Z)=Z \beta\left(1-\frac{d}{Z}\right)+Z \frac{I}{K_{Z}}[R(t)] \quad t<T \\
\psi(Z)=Z \beta\left(1-\frac{d}{Z}\right)+Z \frac{I}{K_{Z}}[R(t)-R(T)] \quad t \geq T
\end{gathered}
$$

where $\beta$ is the initial steady state pressure head, $\mathrm{d}$ is the water table depth, $I$ is the intensity of rainfall, $K_{Z}$ is the hydraulic diffusivity, $T$ is the rainfall end time and $R(t)$ is the response function (Iverson 2000). In this way, we are able to obtain the pressure head $\psi$, which is an input of the stability model.

The stability analysis is based on the limit equilibrium method for an infinite slope. The adopted solution for the infinite slope model is that proposed by Skempton and DeLory (1957), in the form suggested by Iverson (2000). In this equation, the factor of safety is described as a function of depth and time, and it is divided into a time-varying component $F S^{\prime}(Z, t)$ and a steady background component $F S_{0}(Z)$ :

$$
F S(Z, t)=F S_{0}(Z)+F S \prime(Z, t)
$$

the safety factor can be written:

$$
F S(Z, t)=\frac{\tan \varphi}{\tan \alpha}+\frac{c}{\gamma_{s} Z \sin \alpha \cos \alpha}+\frac{\psi(Z, t) \gamma_{w} \tan \varphi}{\gamma_{s} Z \sin \alpha \cos \alpha}
$$

where $\alpha$ is the slope angle, $\varphi$ is the soil friction angle, $\gamma_{s}$ is soil unit weight, $\gamma_{w}$ is the unit weight of groundwater, $c$ is the cohesion, and $Z$ is depth.

For every pixel, the model calculates the factor of safety at increasing depths and allocates the lower FS value found. The computation is automatically repeated at different time steps. Depending on the depth at which the model is working, the sign of pressure head shows if the soil is saturated or unsaturated. If the pressure head is positive, the soil is saturated and the factor of safety can be calculated using directly Eq. 4. Instead, if the pressure head is negative, the soil is unsaturated, and it is necessary to take into account the increase in shear strength due to soil suction. In this case, $c$ is the effective cohesion and can be written in this form (Leoni 2009):

$$
c=c_{0}+c \prime(\psi)
$$

where $c^{\prime}(\psi)$ is the apparent cohesion function of the pressure head $\psi$.

In our analysis, the model will be applied in two test sites on a pixel-by-pixel basis at hourly time steps. At every time step, a new FS map is computed and finally, a summarising FS map of the event is produced assigning to every pixel the lowest FS value assumed in the various time steps (landslides are expected in the pixels which become unstable, even if only for a single time step). A validation is carried out comparing the summarising maps with a landslide inventory in order to quantify correct predictions and errors committed by each simulation. The threshold value of FS $=1$ represents the physical limit for which a slope is ideally considered stable (limit equilibrium). Higher and lower values encountered in the simulations will be interpreted as stable and unstable (respectively) portions of the hill slope. To better highlight the differences in FS distribution due to the use of different soil thickness models, the summarising maps are displayed with an intermediate class of FS values $(1<\mathrm{FS}<1.3)$, which is not considered in the validation. During the validation, sensitivity, specificity and likelihood ratio of the simulations were calculated and used for a quantitative comparison (Beguería 2005; Alatorre and Beguería 2009). Sensitivity is defined as the ratio between true positives (the 
area correctly classified as unstable) and the actually unstable area; specificity is the ratio between false positives (the area erroneously classified as unstable) and the actually stable area; the likelihood ratio is defined as sensitivity/(1-specificity).

In all the simulations performed on each test site, all the input parameters are held constant, excepted soil thickness. The latter influences both the hydrological tool and the stability tool, as it determinates the lower extent to which the calculation of $\psi$ and FS is performed (see Eqs. 1, 2, and 4).

\subsection{Soil thickness models}

To feed in the slope stability model with respect to soil thickness Z, different soil thickness maps, obtained using the following methods, will be used.

\subsubsection{GIST model (and its simplified version)}

The geomorphologically indexed soil thickness (GIST) is an empirical model that combines morphometric attributes with geomorphological and geological factors (Segoni 2008; Segoni and Catani 2008; Catani et al. 2010). This model can be applied at basin scale on a pixel-by-pixel basis using commercial GIS systems.

The model is based on three factors $(\mathrm{C}, \mathrm{P}$ and $\mathrm{S})$, whose value ranges from 0 to 1: A higher value indicates a tendency to have a thicker soil. The values assumed at every pixel by each factor depend on the local value of a corresponding morphometric attribute (curvature for factor $\mathrm{C}$; position along the hill slope profile for factor $\mathrm{P}$; slope gradient for factor $\mathrm{S}$ ), but the relationship linking the morphometric attribute with the corresponding factor is not constant over the entire test area. Factor $\mathrm{C}$ values are basically assumed inversely dependent on curvature values, except where geomorphologic surveys highlights a direct proportionality (e.g. large accumulations of loose material at the footslopes); the area is divided according to the toposequences characterising the hillslopes, and for each subdivision the relationship linking factor $\mathrm{P}$ and hillslope position is independently calibrated; factor S cuts off soil thickness values when the local gradient exceeds a threshold which is different for every lithological class encountered in the area. The product of the three factors is then translated into a soil thickness measure by means of calibration functions, differentiated on a lithological basis and defined by means of a few in situ soil thickness measurements. For further details, see Catani et al. (2010).

In the following applications, also a simplified version of the GIST model will be used. In the simplified GIST model (sGIST henceforth), soil thickness is derived by means of a combination of the three morphometric attributes, without any geomorphological indexing (Catani et al. 2010).

\subsubsection{Topographic models}

The other soil thickness maps that will be used in the simulations are derived by the application of very simple methods, based on the correlation between soil thickness and a single topographic attribute. We refer to these as 'topographic models'. Such methods are widely used (Saulnier et al. 1997; Salciarini et al. 2006; Blesius et al. 2009; De Rose 1996; Godt et al. 2008) because they can be easily and quickly applied at large areas in order to obtain spatially variable soil thickness maps without extensive field surveys.

In our case, the following methods have been used: 
- $\mathrm{Z}$ model: Soil thickness values are inversely proportional to the elevation, according to a linear law derived from a few calibration measures (Saulnier et al. 1997). This model relies on the assumption that in higher locations erosion usually prevails over deposition, producing shallower soils; vice versa at lower elevations, the predominance of deposition usually determines thicker colluvial and alluvial soils.

- S model: Soil thickness values are inversely proportional to the slope gradient, according to a linear law derived from a few calibration measures. Similar approaches are among the most used (Saulnier et al. 1997; Blesius et al. 2009). This model relies on the assumption that on steeper slopes erosive processes are more intense, thus soils are shallower; in contrast, erosion is weaker on flat surfaces so that deposition prevails and thicker colluvial and alluvial soils can be usually found.

- Sexp model: This model is very similar to the previous one, but the relationship between slope gradient and soil thickness is established by an exponential law (thus soil thickness is assumed to decrease more rapidly with increasing slope gradient values). A similar approach has been used by De Rose (1996), Salciarini et al. (2006) and Godt et al. (2008).

The aforementioned methods were applied to the test sites on a pixel-by-pixel basis by means of a GIS system to obtain spatially variable soil thickness maps.

\section{Test site 1: Terzona basin}

\subsection{Test site description}

The first test site, corresponding to the Terzona Creek basin, is $24 \mathrm{~km}^{2}$ wide and is located in the Chianti, Tuscany, Central Italy (Fig. 1). The site is mainly constituted by gentle hills made up of Pliocenic and Quaternary terrains and in the eastern part of the basin a rocky bedrock (Paleocene and Eocene turbiditic flysch) gives rise to higher (up to $512 \mathrm{~m}$ a.s.l.) and rougher reliefs. The hydraulic network has a marked erosive behaviour (also because of the still active tectonic uplift). The area is sparsely urbanised, and it is mainly covered by vineyards, olive groves and, to a lesser extent, small woods.

\subsection{Model application}

In the Terzona case, the slope stability is modelled in response to a 24-h-long rainfall event that occurred in the November 2008. The same amount of rain recorded at 1-h intervals by a rain gauge located $6 \mathrm{~km}$ away from the Terzona basin (in an almost identical geographic and climatic setting) is assumed to uniformly fall over the whole basin. The simulation is subdivided into 24 time steps (one for each recording of the rain gauge). Slope angle was derived from a 10-m grid digital elevation model. A different set of values of mechanical parameters were considered for each geological formation. The values were partly determined by means of geotechnical analyses and partly using literature data related to case studies located near the Terzona basin and pertaining to the same kind of materials (Bianchi et al. 2001; Focardi \& Garzonio 1983; Canuti et al. 1982). To enter soil thickness in the stability model, four different maps were used in distinct simulations. These maps were obtained by means of the methods called S, Z, sGIST and GIST (see Sect. 2.2). For further details on the application of these models to the Terzona test site, see also Catani et al. 2010. Figure 2 shows the very different soil thickness patterns obtained with the aforementioned models. 


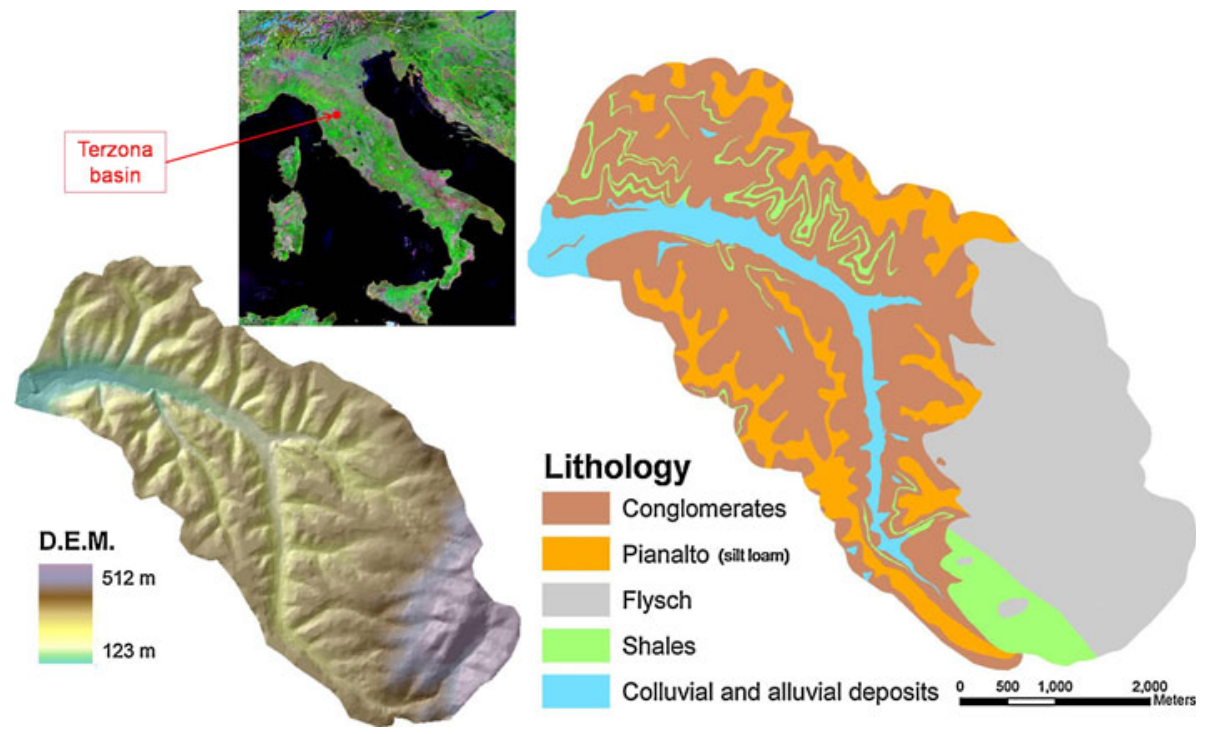

Fig. 1 Location, morphology and lithology of the Terzona basin

S-model returns the shallowest soils in the steepest flanks of the valleys more deeply incised by the hydraulic network, while very deep soils are expected in the alluvial plain and in large sectors of the interfluves occupied by pliocenic terrains (where a flat morphology is often encountered). $\mathrm{Z}$ model returns a very shallow soil at the highest altitudes (rocky relief) which progressively thickens moving downhill and at lower elevations. In the map derived from the simplified version of the GIST model, the dependence from the position along the hill slope is the more clearly noticeable, while using the full geomorphologically indexed soil thickness model the spatial organisation of soil thickness is clearly dependent on the geological characteristics of the area (compare Fig. 2 and Fig. 1).

These patterns were validated by means of 162 measures performed in situ. As it can be clearly seen in Fig. 3, the GIST model-derived soil thickness map had the best agreement: Compared to the other models, the mean absolute error was remarkably lower $(11 \mathrm{~cm}$ versus 27, 53 and $94 \mathrm{~cm}$ ), large residuals were less recurrent, and the frequency distribution was more balanced (while in general Z, S and sGIST models tended to overestimate the soil thickness).

In the next section, we will evaluate the extent to which these errors in the soil thickness maps influenced the slope stability assessment.

\subsection{Results and validation}

By varying the soil thickness pattern, the slope stability model returned very different outputs (Fig. 4). When topographic methods were used to input soil thickness in the stability model, the latter depicted a very widespread instability in the part of the basin dominated by conglomerates. In addition, the S-model also returned FS values near to the limit equilibrium in large sectors of the rocky relief. Using the sGIST model, the instability was returned almost only in the clayey portions of the hillslopes, while $1<\mathrm{FS}<1.3$ values characterised the portion of the basin dominated by conglomerates. The FS map generated using $\mathrm{Z}$ derived from the GIST model strongly differed from the previous ones, 

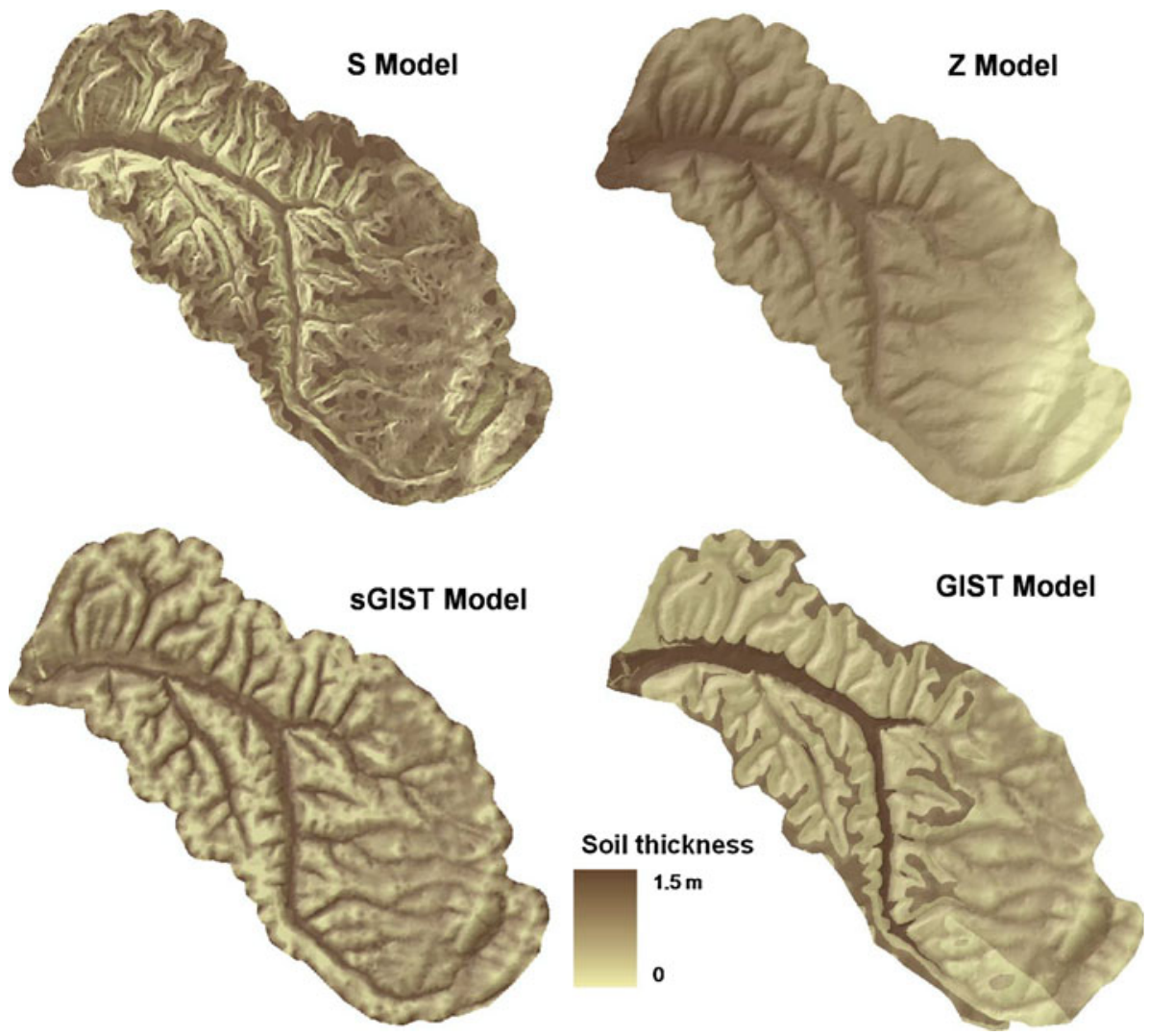

Fig. 2 The four soil thickness maps computed in the Terzona basin

as it was dominated by highly stable slopes and instability was limited to the footslopes and midslopes of the steepest granular soil hillslopes.

A complete validation could not be performed because a field survey highlighted that the rainfall event did not trigger any shallow landslides. However, since the primary object of this work is the assessment of the soil thickness model influence in the factor of safety computation, the number of unstable pixels could be used to compare the reliability of the four models: The best one should help to archive the fewest unstable pixels (Table 1).

The scenario depicted with the GIST model is the most consistent: $98 \%$ of the area was correctly classified as stable, while using the other soil thickness maps the percentage drops to $97 \%$ (sGIST) and 60\% (Z and S). The difference between GIST and sGIST models becomes clearer when the pixels near the limit equilibrium are taken into account (Fig. 4).

\section{Test site 2: Armea basin}

\subsection{Test site description}

The second test site corresponds to the mid-portion and high portion of the Armea Creek catchment (Fig. 5), a small mountain basin located in the Western Alps (Liguria, Northern 


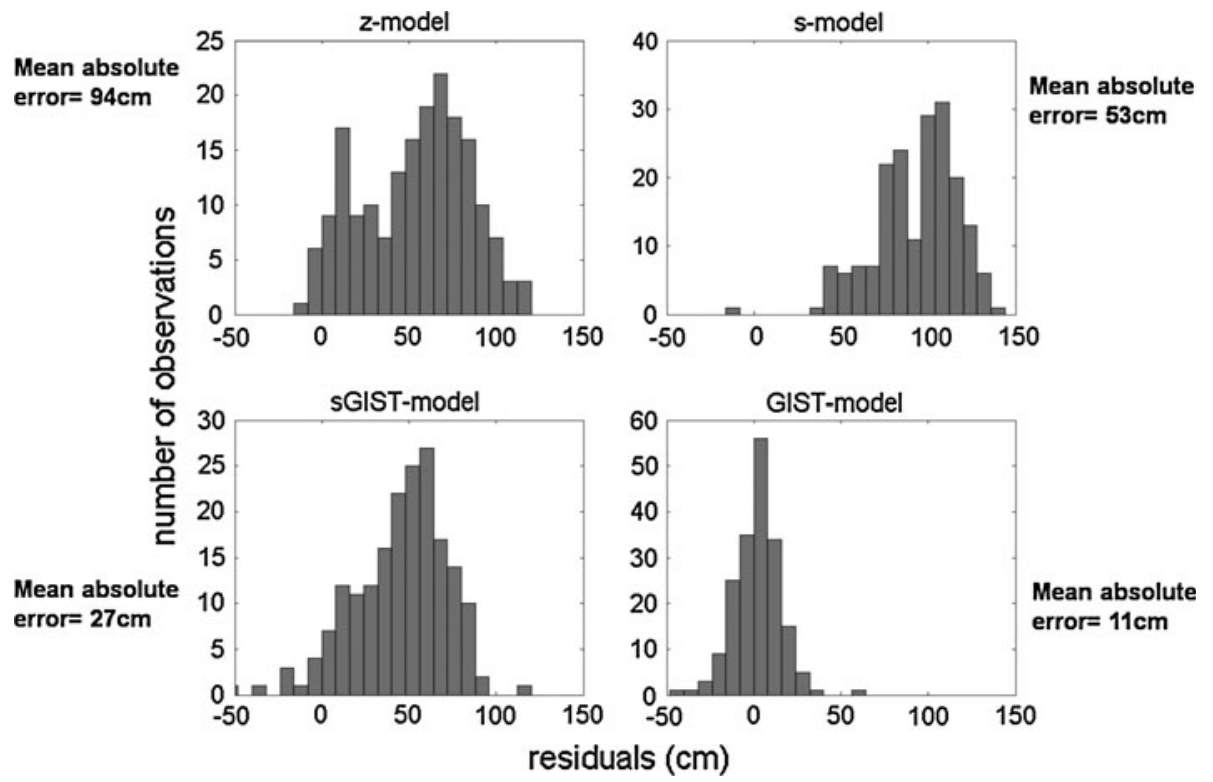

Fig. 3 Frequency distribution of residuals (expressed as the difference between predicted and observed soil thicknesses). Bin size is $8 \mathrm{~cm}$. Modified after Catani et al. 2010

Italy). The basin covers $37 \mathrm{~km}^{2}$, and it is characterised by a high energy of relief, as the hydraulic network flows in deeply incised and narrow valleys from high mountains (up to $1,298 \mathrm{~m}$ a.s.l.) to the sea in a very short distance. From a geological point of view, the study area is dominated by Cretaceous Flysch (limestone and sandstone) with a rather complex structural setting; faults, thrusts, a tectonic window, recumbent folds and polyphase folds give evidence of the great deformation brought by the Alpine orogenesis (Sagri 1980; Sagri 1984; Menardi-Noguera 1988; Merizzi and Seno 1991). The steep slopes and the high energy of relief make the area very prone to erosive processes, and among these, shallow landsliding is one of the most important active shaping factors in the Armea valley. The study area is sparsely urbanised: For the most part, it is occupied by forests, small olive groves are present in the western side of the valley. The population concentrates in the small village of Ceriana (situated at the centre of the area) and in sparse houses scattered over the valley.

\subsection{Model application}

The Armea model run is related to a severe rainfall event that occurred in December 2006, which triggered several shallow landslides. The evolution of the slope stability is computed through 24 time steps $(1 \mathrm{~h}$ each) making use of distributed rainfall maps $(1.75 \mathrm{~km}$ spatial resolution) obtained by means of radar measurements and downscaling techniques (Segoni et al. 2009).

Slope angle was derived from a 5-m resolution digital elevation model.

As in the Terzona case study, a certain spatial variability has been granted to geotechnical parameters of the soil and a distinct value was used for each geological formation. Such values were obtained with laboratory and in situ geotechnical analyses and from data sets already available at the Earth Science Department of Firenze. 

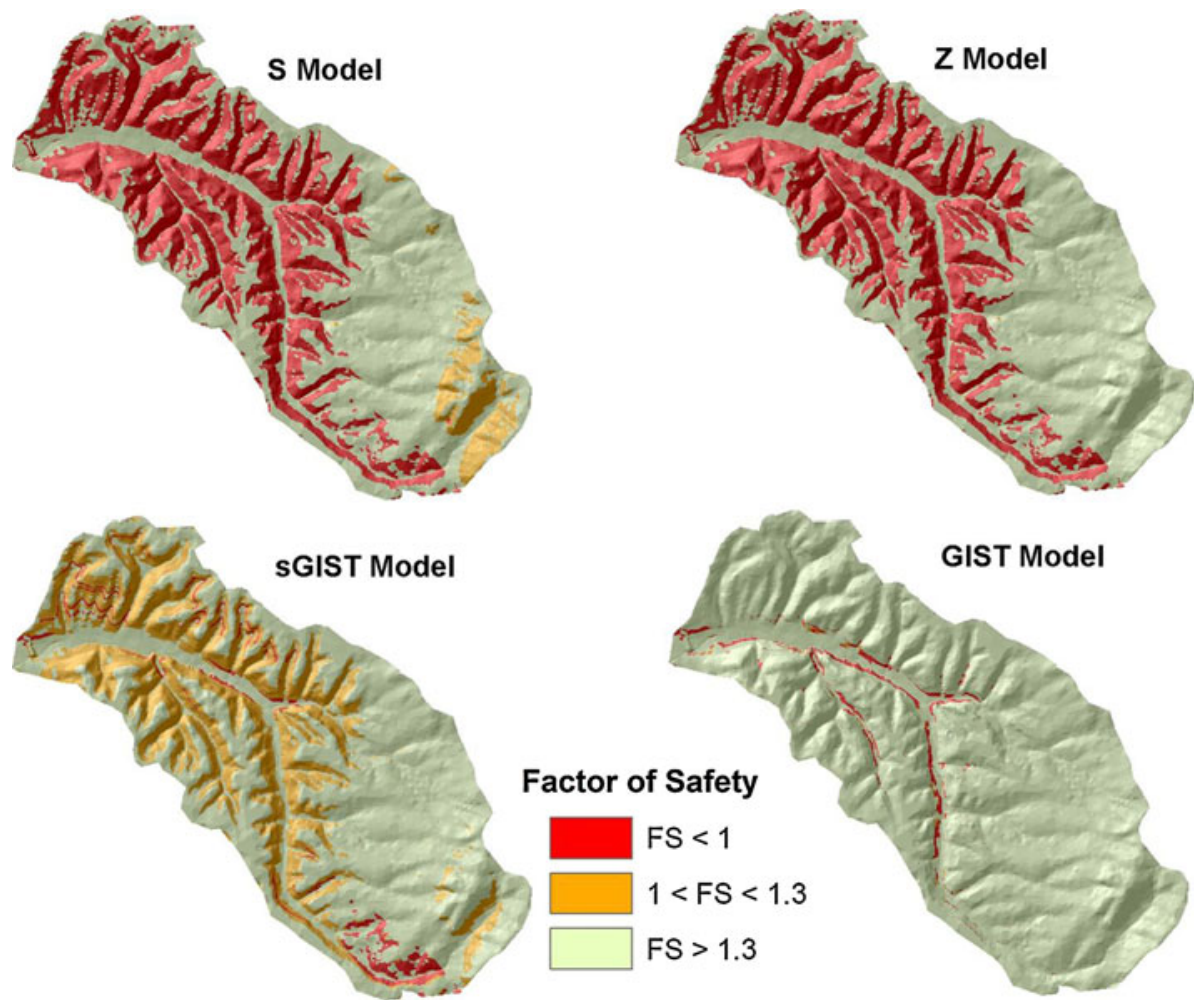

Fig. 4 Factor of safety maps obtained using the soil thickness patterns shown in Fig. 2

Table 1 Validation of the instability maps computed using different soil thickness models

\begin{tabular}{lllll}
\hline & S model $(\%)$ & Z model $(\%)$ & sGIST model $(\%)$ & GIST model (\%) \\
\hline FS $\leq 1$ (false positives) & 40 & 40 & 3 & 2 \\
FS $>1$ (true negatives) & 60 & 60 & 97 & 98 \\
\hline
\end{tabular}

Percentages refer to the areal extent of the Terzona basin classified in each instability class (see text for explanations). Since no landslides actually occurred during the event, the percentage of FS $\leq 1$ should be considered as the false positive rate

As for soil thickness maps, the Z, S, Sexp and GIST models (see Sect. 2.2) were applied to the Armea basin obtaining very different results (Fig. 6). As in the previous case study, slope- and elevation-dependent soil thickness maps exhibit a spatial variability identical to that of the attribute used for its derivation. Despite that, the two gradient-based models returned very different results as the exponential relationships (Sexp model) tended to depict shallower soils than the linear one ( $\mathrm{S}$ model). The GIST model-derived soil thickness pattern, in turn, is evidently influenced by the lithology of the bedrock and by the relative position along the hillslope profile.

A number of direct soil thickness measures varying from 91 to 154 (depending on the number of measures required for the calibration of each model) were used to validate these maps (Fig. 7). As in the Terzona basin, $\mathrm{Z}$ and $\mathrm{S}$ models had the worst performance, with 


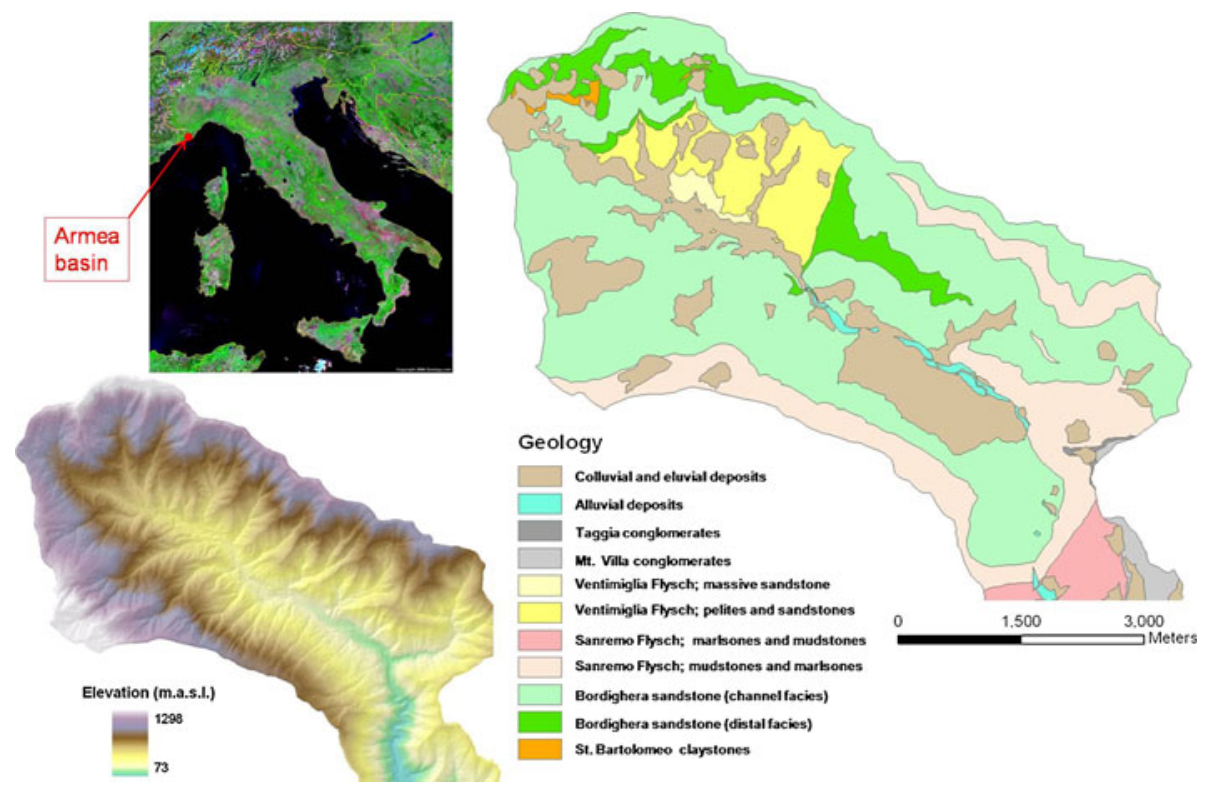

Fig. 5 Location, morphology and lithology of the Armea basin

high mean absolute error, high frequency of large residuals and a pronounced tendency to overestimate soil thickness. Sexp model returned quite good results $(45 \mathrm{~cm}$ mean absolute error), but the frequency distribution of the residuals showed a proneness to underestimation. The soil thickness map obtained with the GIST model seemed more reliable than the others: Mean absolute error was lower $(23 \mathrm{~cm})$, very large residuals were less frequent and no marked tendency to overestimation or underestimation was revealed by the frequency distribution of the residuals.

\subsection{Results and validation}

To assess the impact that different soil thickness patterns can have on slope stability evaluation, the factor of safety calculations were repeated four times using the different models to input soil thickness. As can be seen from Fig. 8, it led to very different results.

While using $\mathrm{Z}$ and $\mathrm{S}$ models, a generalised instability affected the largest part of the studied area, Sexp model depicts a diametrically opposite scenario, in which the Armea basin is stable almost everywhere. The result obtained using the GIST model is intermediate between these two very extreme conditions: Instability affected small sectors of the basin predominantly located in hollows with limestone bedrock. These maps were validated with an inventory of the shallow landslides triggered by the rainfall event used in the simulations. The inventory includes 141 shallow movements (mainly debris flows and soil slips) that damaged properties, roads and assets (in addition to causing injuries to one person) (Segoni et al. 2009). As can be seen also from Fig. 9, the landslide population is characterised by events with very small sliding area (one half covers areas smaller than $100 \mathrm{~m}^{2}$ ) and only a few phenomena with relevant magnitude.

Focusing on a small but representative portion of the Armea basin (Fig. 10), we can better understand how the different soil thickness maps used in the simulation influence the 


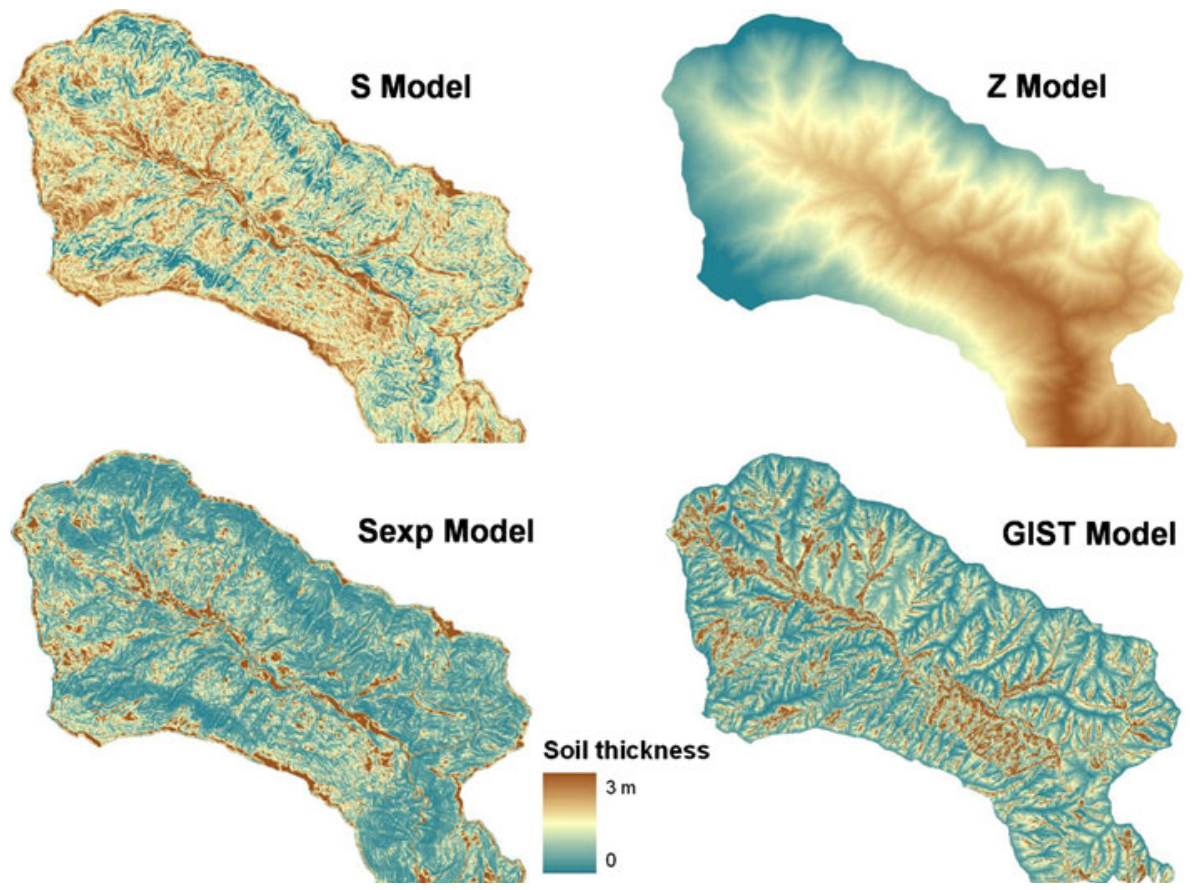

Fig. 6 Soil thickness maps computed in the Armea basin by means of four different models
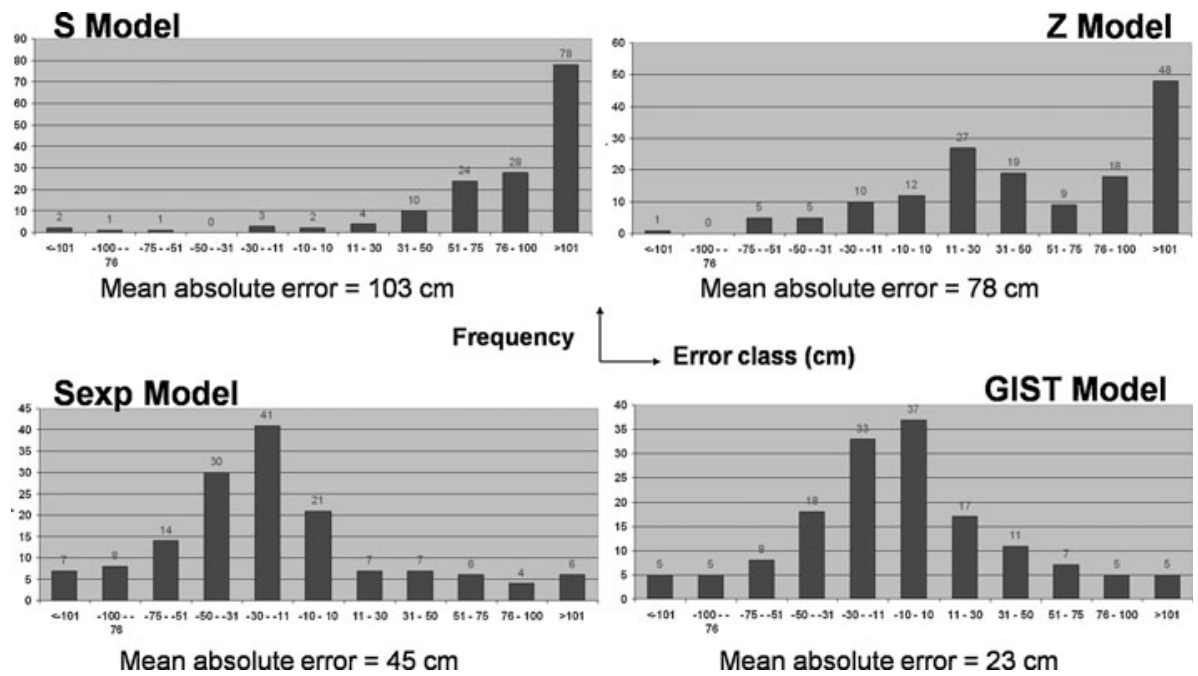

Fig. 7 Frequency distribution of residuals (expressed as the difference between predicted and observed soil thicknesses). Note that $y$-axis scale varies from a histogram to another

modelling of the most destructive debris flows that occurred in the whole basin. Using the $\mathrm{S}$ and $\mathrm{Z}$ models, all debris flows were correctly identified, but a very high number of false positives were also computed. The use of Sexp model, on the contrary, led to an unrealistic 

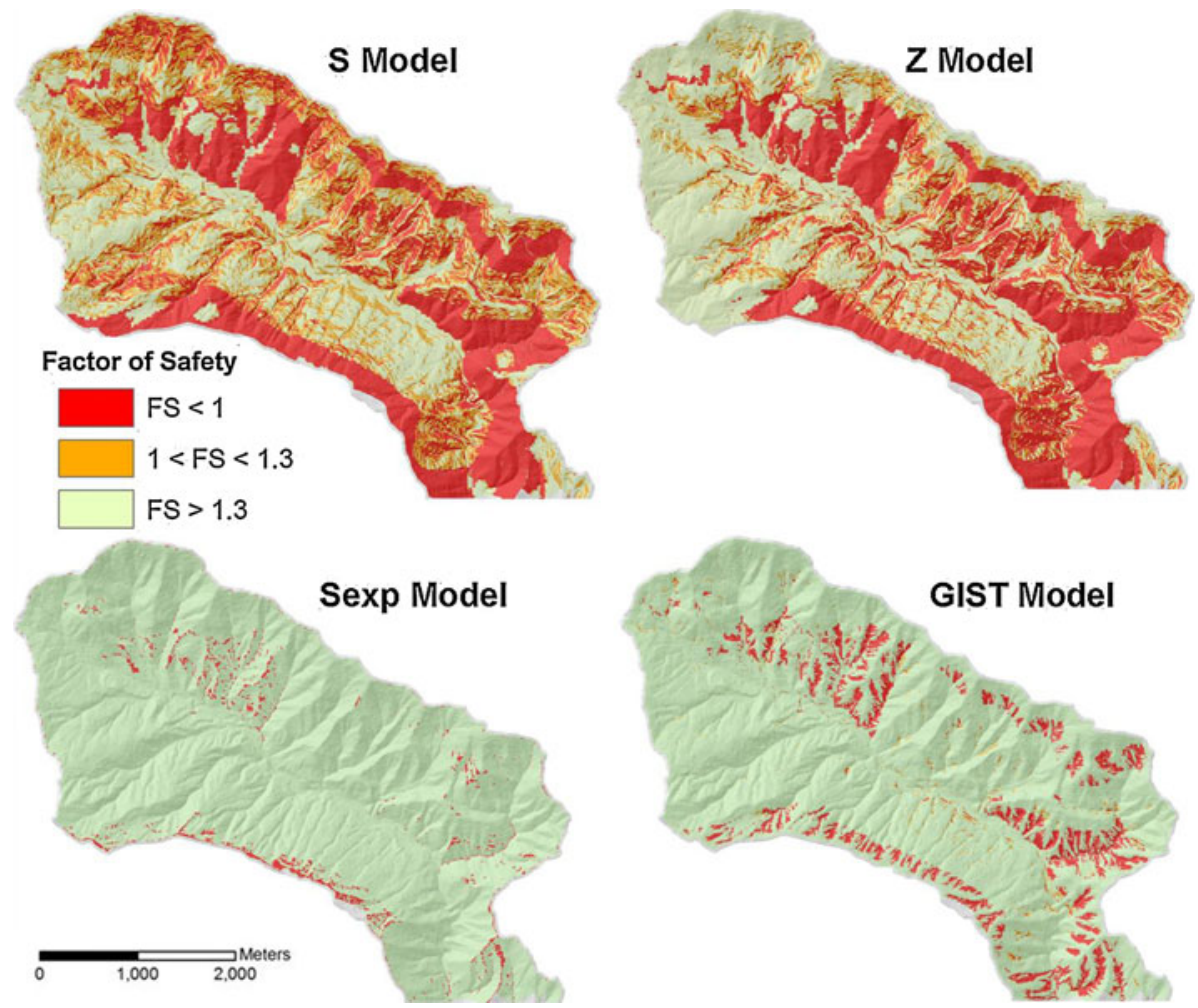

Fig. 8 Factor of safety maps obtained using the soil thickness patterns shown in Fig. 6

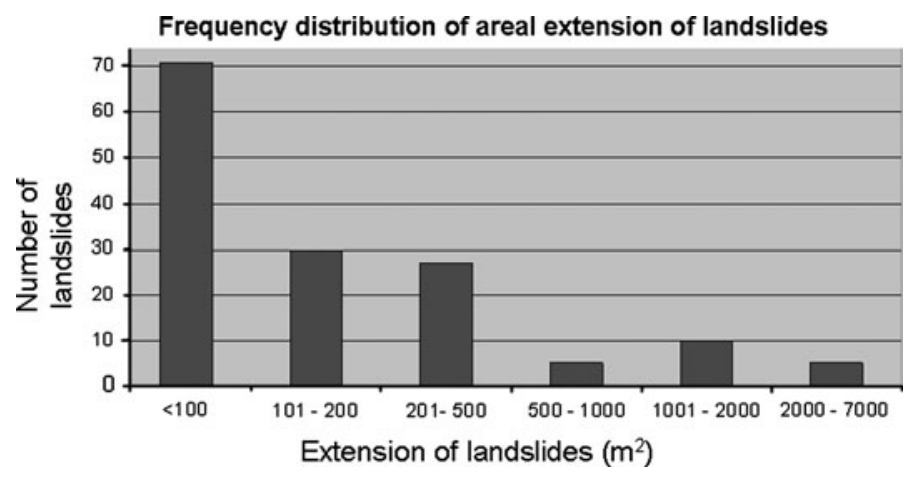

Fig. 9 Frequency distribution of the areal extent of landslides (sliding area) that occurred on December 2006 in the Armea basin

portrayal of a completely stable hillslope. The soil depth map obtained with the GIST model produced a more realistic instability map: Unstable pixels were limited to the area of initiation of the debris flows, and false positives were limited to the surrounding areas. The missed landslide of Fig. 9 is the only large landslide which the GIST model failed to detect. Field survey evidenced that its triggering can be connected mainly to a set of 


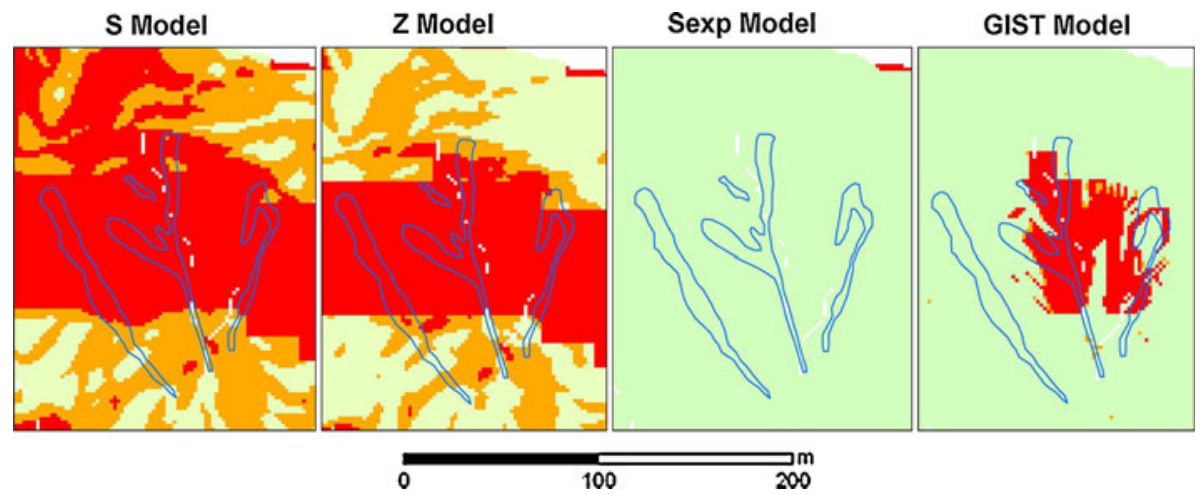

Fig. 10 Inventoried landslides (blue lines) compared with the results of the simulation in a zoom over a particularly representative area. Red indicates highly unstable areas, orange refers to moderately unstable areas. Stable areas are in green

external factors not accounted for in the stability modelling but of great importance in influencing shallow landsliding: The location in an area affected by recent wildfire (Cannon et al. 2001), the exceptionally fractured bedrock (Sas and Eaton 2008) and the presence of a road cut (Collins 2008).

The behaviour observed above at a localised scale was confirmed over the entire basin (Tables 2 and 3). Using $\mathrm{S}$ and $\mathrm{Z}$ models to input soil thickness in the simulation, a great percentage of landslides were correctly associated with the highest instability class (Table 2) but at the same time a high number of false positives were returned (Table 3 ). In these two cases, the validation showed a highly sensitive yet low specificity model. In fact, only $60 \%$ (S model) and 61\% ( $\mathrm{Z}$ model) of the area that did not experience landsliding was correctly identified as stable. The use of Sexp model returned opposite results: False positives were very low ( $97.3 \%$ of the stable area correctly classified as such), but very few landslides were identified (only 4 of 141 , corresponding to the $5 \%$ of the total area that resulted affected by landslides). Between these two extremes, GIST model results were

Table 2 True positives and false negatives in the Armea basin simulation

\begin{tabular}{|c|c|c|c|c|c|c|c|c|}
\hline \multirow[b]{2}{*}{ Instability class } & \multicolumn{2}{|c|}{$\mathrm{S}$ model } & \multicolumn{2}{|c|}{$\mathrm{Z}$ model } & \multicolumn{2}{|c|}{ Sexp model } & \multicolumn{2}{|c|}{ GIST model } \\
\hline & $\mathrm{m}^{2}$ & $\%$ & $\mathrm{~m}^{2}$ & $\%$ & $\mathrm{~m}^{2}$ & $\%$ & $\mathrm{~m}^{2}$ & $\%$ \\
\hline $\mathrm{FS} \leq 1$ (true positives) & 52,750 & 87 & 55,950 & 81 & 3,125 & 5 & 24,240 & 40 \\
\hline FS $>1$ (false negatives) & 7,850 & 13 & 11,575 & 19 & 57,475 & 95 & 36,360 & 60 \\
\hline
\end{tabular}

Statistics are computed considering the areal extent of the landslides classified in each stability class

Table 3 False positives and true negatives committed in the Armea simulation

\begin{tabular}{lllll}
\hline Instability class & S model $(\%)$ & Z model $(\%)$ & Sexp model (\%) & GIST model (\%) \\
\hline FS $\leq 1$ (false positives) & 40 & 39 & 3 & 9 \\
FS $>1$ (true negatives) & 60 & 61 & 97 & 91 \\
\hline
\end{tabular}

Percentages refer to the portion of the Armea basin which was not affected by landslides classified into each stability class 
more balanced: The $40 \%$ of the area affected by landslides is classified as unstable and false positives accounted for only $9 \%$ of the unaffected area.

The likelihood ratio (Lr), defined as sensitivity/(1-specificity), can be used as an index of the overall performance of the models (Beguería 2005), to assess which one obtained the best performance. In this light, the use of GIST model gave the best outcome $(\mathrm{Lr}=4.44)$, followed by Sexp (2.43), S (2.20) and Z (2.09).

\section{Discussion}

Considering different soil thickness models in the simulations, remarkably different results were obtained at both test sites, confirming that slope stability models based on the infinite slope theory are very sensitive to soil thickness (Johnson and Sitar 1990; Wu and Sidle 1995; Van Asch et al. 1999; Segoni et al. 2009). Infinite slope-based approaches are often believed to overestimate instability related to shallow landsliding; our simulations show that, at least in our case studies, an important contribution to overestimation can be provided by the errors made by feeding the slope stability model with inaccurate soil thickness maps.

The analyses showed a typical result: Increasing the sensitivity of the model (i.e. its ability to correctly predict the positive cases), its specificity was negatively affected (i.e. a higher rate of false positives was obtained). The errors generated in modelling the spatial organisation of soil thickness seem correlated with the errors of the derived instability maps, as in both test sites they appear proportional. In fact when soil thickness maps are affected by large overestimation, the derived instability map is overestimated accordingly. In both test sites, the $\mathrm{S}$ model returned the highest overestimation of soil thickness and the highest underestimation of the factor of safety. The same evidence repeats, at a slightly lesser extent, with the Z model. The sGIST model returned a soil thickness map affected by low error, but overestimation, even if small in magnitude, was predominant. That led to a FS map affected by systematic instability in the clayey terrains and by the predominance of moderately unstable areas in conglomerates, highlighting that the systematicity of soil thickness errors may be more important than their mean magnitude. This is further confirmed by the behaviour of Sexp model, which produced an evident (and very unsafe) overestimation of factor of safety as a consequence of its tendency to underestimate soil thickness, despite a rather low mean absolute error.

The use of GIST model leads to accurate soil thickness predictions in the Terzona basin, providing very consistent slope stability assessment, but validation could be performed considering only the occurrence of false positives. In the Armea basin, the results are more useful: The soil thickness pattern is more precise than the others methods employed, and the results of the slope stability model are more accurate (higher likelihood ratio). Even from a qualitative point of view the GIST-derived instability map proved to be the more consistent: The true positives rate $(40 \%)$ is not so high but it includes all the large landslides except one (as discussed in Sect. 4.3), while the missed events are very small $\left(105 \mathrm{~m}^{2}\right.$ mean area). In addition, the other simulations were affected by systematic errors: Sexp-derived FS map depicted an almost uniformly stable scenario, while Z and S models identified a high percentage of landslides only because they predicted an extraordinarily broad instability over the whole area. 


\section{Conclusions}

In this paper, we made a comparison between various methods to enter soil thickness as a spatial variable in basin scale slope stability model. We used a slope stability model that is a combination of a simplified solution of Richards' infiltration equation for the hydrological model, and an infinite slope model with soil suction effect for the mechanical stability. Soil thickness was entered in the stability model using spatially variable maps obtained with different methods: (a) linear correlation with elevation; (b) linear correlation with slope gradient; (c) exponential correlation with slope gradient; (d) combination of curvature, position along the hillslope profile and slope gradient; (e) a more complex model that uses the same topographic attributes of the previous one in conjunction with geological and geomorphological factors.

Results confirmed that the factor of safety is very sensitive to soil thickness and that in general a more reliable soil thickness map, combined with infinite slope based models, improves spatial distribution of FS values at basin scale. We verified that in a deterministic approach the uncertainty in the FS calculation can be reduced by applying more precise input data (i.e. soil thickness), and we demonstrated that the same stability model can become more sensitive or more specific depending on the input data.

Despite slope-based methods are the most used in literature to derive soil thickness (De Rose 1996, Salciarini et al. 2006; Godt et al. 2008), in both the tested sites they returned poor results. Moreover, we verified that the use of an exponential (rather than a linear) relationship does not improve the results; on the contrary in the Armea basin, they were worsened. The use of a combination of three morphometric attributes (sGIST model, Catani et al. 2010) depicted more consistent soil thickness maps and consequently improved the performance of the stability model, but a further substantial improvement was obtained when using soil thickness patterns derived from a model that encompasses geomorphological criteria (GIST model, Catani et al. 2010).

Open Access This article is distributed under the terms of the Creative Commons Attribution Noncommercial License which permits any noncommercial use, distribution, and reproduction in any medium, provided the original author(s) and source are credited.

\section{References}

Alatorre LC, Beguería S (2009) Identification of active erosion and erosion risk areas using remote sensing in a badlands landscape on marls in the central Spanish Pyrenees. Catena 76:182-190

Beguería S (2005) Validation and evaluation of predictive models in hazard assessment and risk management. Nat Hazards 37:315-329

Bianchi F, Catani F, Moretti S (2001) Environmental accounting of hillslopes processes in Central Tuscany, Italy. In: Villacampa Y, Brebbia CA, Uso JL (eds) Ecosystems and sustainable development III. Advances in ecological sciences. WIT Press, Alicante, pp 229-238

Blesius L, Weirich F (2009) The use of high-resolution satellite imagery for deriving geotechnical parameters applied to landslide susceptibility. ISPRS Hannover Workshop 2009, Hannover, Germany, June 2-5, 2009

Cannon SH, Kirkham RM, Parise M (2001) Wildfire-related debris-flow initiation processes, Storm King Mountain, Colorado. Geomorphology 39(3-4):171-188

Canuti P, Focardi P, Garzonio CA, Rodolfi G, Vannocci P, Boccacci L, Frascati F, Moretti S, Salvi R (1982) Stabilità dei versanti nell'area rappresentativa di Montespertoli (Firenze): Carta geologico-tecnica, morfometrica e dell'uso del suolo. Tipografia S.EI.Ca, Firenze

Casadei M, Dietrich WE, Miller NL (2003) Testing a model for predicting the timing and location of shallow landslide initiation in soil-mantled landscapes. Earth Surf Proc Land 28(9):925-950 
Catani F, Casagli N, Ermini L, Righini G, Menduni G (2005) Landslide hazard and risk mapping at catchment scale in the Arno River basin. Landslides 2:329-342

Catani F, Segoni S, Falorni G (2010) An empirical geomorphology-based approach to the spatial prediction of soil thickness at catchment scale. Water Resour Res 46:W05508. doi:10.1029/2008WR007450

Collins TK (2008) Debris flows caused by failure of fill slopes - early detection, warning and loss prevention. Landslides 5(1):107-119

Crosta GB (1998) Regionalisation of rainfall thresholds: an aid to landslide hazard evaluation. Environ Geol 35:131-145

De Rose RC (1996) Relationships between slope morphology, regolith depth, and the incidence of shallow landslides in eastern Taranaki hill country. Zeitschrift für Geomorphologie Supplementband 105:49-60

Dietrich WE, McKean J, Bellugi D, Perron JT (2008) The prediction of shallow landslide location and size using a multidimensional landslide analysis in a digital terrain model. Proceedings of the Fourth International Conference on Debris-Flow Hazards Mitigation. http://www-eaps.mit.edu/faculty/ perron/files/Dietrich08.pdf

Focardi P, Garzonio CA (1983) La frana di Marcialla (Certaldo, FI). Geologia Tecnica 1(83):13-19

Gessler PE, Chadwick OA, Chamran F, Althouse L, Holmes K (2000) Modeling soil-landscape and ecosystem properties using terrain attributes. Soil Sci Soc Am J 64:2046-2056

Godt JW, Baum RL, Savage WZ, Salciarini D, Schulz WH, Harp EL (2008) Transient deterministic shallow landslide modeling: Requirements for susceptibility and hazard assessments in a GIS framework. Eng Geol 102(3-4):214-226

Guzzetti F, Carrara A, Cardinali M, Reichenbach P (1999) Landslide hazard evaluation: a review of current techniques and their application in a multi-scale study, Central Italy. Geomorphology 31:181-216

Guzzetti F, Peruccacci S, Rossi M, Stark CP (2007) Rainfall thresholds for the initiation of landslides in central and southern Europe. Meteorol Atmos Phys 98:239-267

Guzzetti F, Peruccacci S, Rossi M, Stark CP (2008) The rainfall intensity-duration control of shallow landslides and debris flows: an update. Landslides 5:3-17

Iverson R (2000) Landslide triggering by rain infiltration. Water Resour Res 36:1897-1910

Johnson KA, Sitar N (1990) Hydrologic conditions leading to debris-flow initiation. Can Geotech J 27:789-801

Khazai B, Sitar N (2000) Assessment of seismic slope stability using GIS modeling. Geogr Inf Sci 6(2):121-128

Leoni L (2009) Shallow landslides triggered by rainfall: integration between ground-based weather radar and slope stability models in near-real time. Unpublished $\mathrm{PhD}$ thesis, Università degli Studi di Firenze, Department of Earth Sciences, Florence, Italy

Menardi-Noguera A (1988) Structural evolution of a briançonnais cover nappe, the Caprauna-Armetta unit (Ligurian Alps, Italy). J Struct Geol 10:625-637

Merizzi G, Seno S (1991) Deformation and gravity-driven translation of the S. Remo-M. Saccarello nappe (helminthoid flysch, Ligurian Alps). Boll Soc Geol Ital 110:757-770

Montrasio L, Valentino R, Losi GL (2009) Rainfall-induced shallow landslides: a model for the triggering mechanism of some case studies in Northern Italy. Landslides 6:241-251. doi:10.1007/s10346009-0154-7

Pelletier JD, Rasmussen C (2009) Geomorphically based predictive mapping of soil thickness in upland watersheds. Water Resour Res 45:W09417. doi:10.1029/2008WR007319

Revellino P, Guadagno FM, Hungr O (2008) Morphological methods and dynamic modelling in landslide hazard assessment of the Campania Apennine carbonate slope. Landslides 5:59-70

Rossi G (in preparation) A physically based distributed slope stability simulator to analyze shallow landslides triggering in real time and at large scale. PhD thesis, Università degli Studi di Firenze, Department of Earth Sciences, Florence, Italy

Sagri M (1980) Le arenarie di Bordighera: una conoide sottomarina nel bacino di sedimentazione del flysch ad Elmintoidi di San Remo (Cretaceo superiore, Liguria occidentale). Boll Soc Geol Ital 98(99): $205-226$

Sagri M (1984) Litologia, stratimetria e sedimentologia delle torbiditi di piana di bacino del flysch di San Remo (cretaceo superiore, Liguria occidentale). Mem Soc Geol Ital 28:577-586

Salciarini D, Godt JW, Savage WZ, Conversini R, Baum RL, Michael JA (2006) Modelling regional initiation of rainfall-induced shallow landslides in the eastern Umbria Region of central Italy. Landslides 3:181-194

Sas RJ Jr, Eaton LS (2008) Quartzite terrains, geologic controls, and basin denudation by debris flows: their role in long-term landscape evolution in the central Appalachians. Landslides 5(1):97-106

Saulnier GM, Beven K, Obled C (1997) Including spatially variable effective soil depths in TOPMODEL. J Hydrol 202:158-172 
Savage WZ, Godt JW, Baum RL (2004) Modelling time-dependent areal slope stability. In: Lacerda WA, Erlich M, Fontoura SAB, Sayao ASF (eds) Landslides: Evaluation and Stabilisation, Proceedings of the 9th International Symposium on Landslides. A.A. Balkema Publishers, London, pp 23-36

Schuster RL, Fleming RW (1986) Economic losses and fatalities due to landslides. Am As Eng Geol Bull 23:11-28

Segoni S (2008) Elaborazione ed applicazioni di un modello per la previsione dello spessore delle coperture superficiali, Unpublished PhD thesis, Università degli Studi di Firenze, Department of Earth Sciences, Florence, Italy

Segoni S, Catani F (2008) Modelling soil thickness to enhance slope stability analysis at catchment scale. 33rd international geological congress, Oslo, Norway, 6-14 August 2008 http://www.cprm.gov.br/33 IGC/1345585.html

Segoni S, Leoni L, Benedetti AI, Catani F, Righini G, Falorni G, Gabellani S, Rudari R, Silvestro F, Rebora N (2009) Towards a definition of a real-time forecasting network for rainfall induced shallow landslides. Nat Hazards Earth Syst Sci 9:2119-2133

Tesfa TK, Tarboton DG, Chandler DG, McNamara JP (2009) Modelling soil depth from topographic and land cover attributes. Water Resour Res 45:W10438. doi:10.1029/2008WR007474

Van Asch TWJ, Buma J, Van Beek LPH (1999) A view on some hydrological triggering systems in landslides. Geomorphology 30(1):25-32 (8)

Wu W, Sidle RC (1995) A distributed slope stability model for steep forested basins. Water Resour Res 31(8):2097-2110 